\title{
Espraiamento urbano e os impactos ambientais dos resíduos sólidos na Bacia Hidrográfica do Rio Gramame, em João Pessoa-PB
}

\author{
Urban sprawl and environmental impacts of municipal solid waste in the Basin \\ Gramame River in Joao Pessoa -PB.
}

La urbanización y el impacto ambiental de los residuos sólidos urbanos en la cuenca del río Gramame en Joao Pessoa -PB.

Cynthia Alves Félix de Sousa Mestranda em Engenharia Civil e Ambiental, UFPB, Brasil cynthiaalvesfs@hotmail.com

Milena Dutra da Silva Professora Doutora, UFAL, Brasil dutra_ms@hotmail.com

José Augusto Ribeiro da Silveira

Professor Doutor, UFPB, Brasil ct.laurbe@gmail.com 


\section{Periódica Eletrônica

\section{RESUMO}

A urbanização das cidades, tanto na esfera global como nacional tem sido associada a problemas socioeconômicos e ambientais como, por exemplo, a redução dos espaços verdes e principalmente a poluição ambiental. Conforme ocorreu a urbanização, o constante crescimento populacional foi acompanhado pela produção incessante de resíduos, gerando diversos impactos ambientais, devido em parte a sua inadequada disposição. Estas questões relativas ao crescimento urbano e os impactos ambientais tem se constituído em um desafio às cidades, tornando-se cada vez mais relevantes as discussões acerca da necessidade de medidas que promovam sustentabilidade nos processos de desenvolvimento das cidades. A urbanização de João Pessoa, PB, se deu de maneira rápida e espraiada, direcionada para o sul do município, caracterizada pelos grandes espaços naturais necessários a qualidade ambiental, como por exemplo, a Bacia do Rio Gramame. Esta pesquisa objetivou diagnosticar os impactos ambientais urbanos provocados pelos resíduos sólidos urbanos na Bacia Hidrográfica do Rio Gramame, em João Pessoa-PB. Para tanto, realizou-se um levantamento dos impactos ambientais seguido da espacialização dos pontos de despejo de resíduos na área de estudo. Os resultados alcançados possibilitaram a geração de reflexões acerca do modelo de crescimento urbano da cidade na direção da Bacia Hidrográfica do Rio Gramame, bem como as carências nos sistemas de saneamento urbano e políticas de proteção ambiental.

PALAVRAS-CHAVE: Espraiamento Urbano. Impactos Ambientais. Resíduos Sólidos.

\section{ABSTRACT}

The urbanization of cities, both at the global level and national levels has been linked to socioeconomic and environmental problems, as, for example, the reduction of green spaces and especially environmental pollution. As urbanization increased, the continuous population growth was accompanied by incessant production of waste, generating various environmental impacts, due in part to their inappropriate disposal. These issues regarding urban growth and environmental impacts has constituted a challenge to the cities, increasingly becoming relevant discussions about the need for actions promoting sustainability in the development processes of cities. The urbanization of João Pessoa, PB, occurred in a fast and dispersed mode, directed to the south of it, characterized by large natural spaces necessary to the environmental quality, such as the River Basin Gramame. This study aimed to diagnose the urban environmental impacts of urban solid waste in the Basin Gramame River in Joao Pessoa-PB. Therefore, a survey of the environmental impacts followed by the spatial distribution of waste disposal points in the study área was held. The results achieved have enabled the generation of reflections about the urban growth model of the city toward the Basin Gramame River, as well as deficiencies in urban sanitation systems and environmental protection policies.

KEYWORDS: Urban sprawl. Environmental Impacts. Waste.

\section{RESUMEN}

La urbanización de las ciudades, tanto a nivel mundial como a nivel nacional se ha relacionado con problemas socioeconómicos y ambientales, tales como la reducción de los espacios verdes y la contaminación ambiental. A medida que aumenta la urbanización, el crecimiento constante de la población fue acompañada por la producción incesante de residuos, generando diversos impactos ambientales, debido en parte a su eliminación inadecuada. Es un reto para las ciudades, estas cuestiones relacionadas con el crecimiento urbano y los impactos ambientales se vuelven cada vez más relevantes discusiones sobre la necesidad de medidas para promover la sostenibilidad en los procesos de desarrollo de las ciudades. Urbanización de João Pessoa, PB, se produjo rápidamente y se dispersa de forma, dirigida al sur de la misma, que se caracteriza por grandes espacios naturales que se requieran calidad del medio ambiente, tales como la cuenca del río Gramame. Este estudio tuvo como objetivo diagnosticar impactos ambientales urbanos de residuos sólidos urbanos en la cuenca del río Gramame en Joao Pessoa-PB. Por lo tanto, se llevó a cabo un estudio de los impactos ambientales, seguido de la distribución espacial de los puntos de eliminación de residuos en el área de estudio. Los resultados obtenidos han permitido la generación de reflexiones sobre el modelo de crecimiento urbano de la ciudad hacia el Gramame y deficiencias en los sistemas de saneamiento urbano y la política de protección del medio ambiente de cuenca.

PALABRAS CLAVE: Espraiamento Urbano. Impactos ambientales. Resíduos Sólidos. 


\section{INTRODUÇÃO}

Os resíduos sólidos constituem atualmente um problema complexo no âmbito das questões relativas à sustentabilidade ambiental das cidades. Conforme a urbanização avançou, o constante crescimento populacional foi acompanhado por uma produção incessante de resíduos, gerando diversos impactos ambientais devido à sua inadequada disposição.

Esta conjuntura trouxe relevância às discussões sobre medidas de prevenção e correção dos impactos ambientais associados aos resíduos sólidos, gerando cada vez mais reflexões acerca da geração e destinação final dos resíduos no atual modelo de desenvolvimento urbano.

A problemática se repete em diversas cidades brasileiras, sejam elas de pequeno, de médio ou de grande porte, onde as áreas próximas ou inseridas em bacias hidrográficas, por serem naturalmente sensíveis a determinados usos, enfrentam esta crescente e problemática realidade (CARDOSO et al., 2015; PANTALENA e MAIA ,2014).

As degradações ambientais correlacionadas à urbanização intensa, crescente, espraiada e também socioeconomicamente problemática, são recorrentes mundo afora, mas também são corriqueiras nas dimensões nacional, regional e local no Brasil. Esta realidade traz à tona a importância não só da existência de políticas de proteção ambiental, mas também da efetividade da legislação urbanística e ambiental direcionada para esta finalidade, de modo a reduzir e prevenir os impactos ambientais urbanos que tendem a aumentar em grau e extensão. No município de João Pessoa, os resíduos domiciliares da cidade quando coletados, são encaminhados para disposição final no Aterro Sanitário Metropolitano. No entanto, o sistema de coleta (que envolve do acondicionamento até a destinação final) ainda apresenta precariedade principalmente nos bairros mais periféricos, cuja localização de pontos de despejo de resíduos é frequente.

Assim, tendo em vista as problemáticas relativas aos impactos ambientais decorrentes da urbanização, principalmente no que ser refere ao modelo espraiado de crescimento urbano, esta pesquisa se propôs a investigar os impactos ambientais da disposição de resíduos sólidos na Bacia Hidrográfica do rio Gramame, em João Pessoa-PB.

A área de estudo, no início dos anos 80 apresentou um quadro de intenso de crescimento urbano espraiado, tornando-se lento e constante a partir do início da década de 90 . Tal avanço urbano ocorre direcionado para as áreas limítrofes da região sul da cidade, onde se encontram fragmentos de remanescentes de mata atlântica e demais áreas protegidas essenciais ao equilíbrio ecossistêmico, que apesar de sua importância tem enfrentado impactos ambientais associados à urbanização.

\section{OBJETIVOS}

Como objetivo principal tem-se o diagnóstico dos impactos ambientais urbanos decorrentes da disposição de resíduos sólidos na Bacia do Rio Gramame em João Pessoa, PB. Para subsidiar as análises e discussões dos resultados, objetivou-se também compreender o processo de espraiamento urbano e realizar um mapeamento dos pontos de despejo de resíduos sólidos.

\section{METODOLOGIA}

A metodologia desta pesquisa é caracterizada como um estudo diagnóstico dos impactos ambientais urbanos ao meio ambiente, decorrentes do espraiamento do tecido urbano, tendo como área de estudo a Bacia hidrográfica do Rio Gramame, em João Pessoa-PB (Figura 3). 


\section{Periódica Eletranica}

\section{Fórum Ambiental}

Volume 14, Número 1, 2018

da Alta Paulista

ISSN 1980-0827

Este recorte espacial teve como critérios essenciais aspectos urbanos e ambientais. No que se refere ao primeiro, tem-se principalmente o modelo de expansão urbana verificado nas últimas três décadas, bem como vetores de expansão urbana e os limites de avanço urbano, especialmente os espaços verdes e áreas rurais. $O$ aspecto ambiental se refere à importância ecológica geral que a vegetação remanescente e a presença de um rio como o Gramame exerce sobre seu entorno (Figura 1).

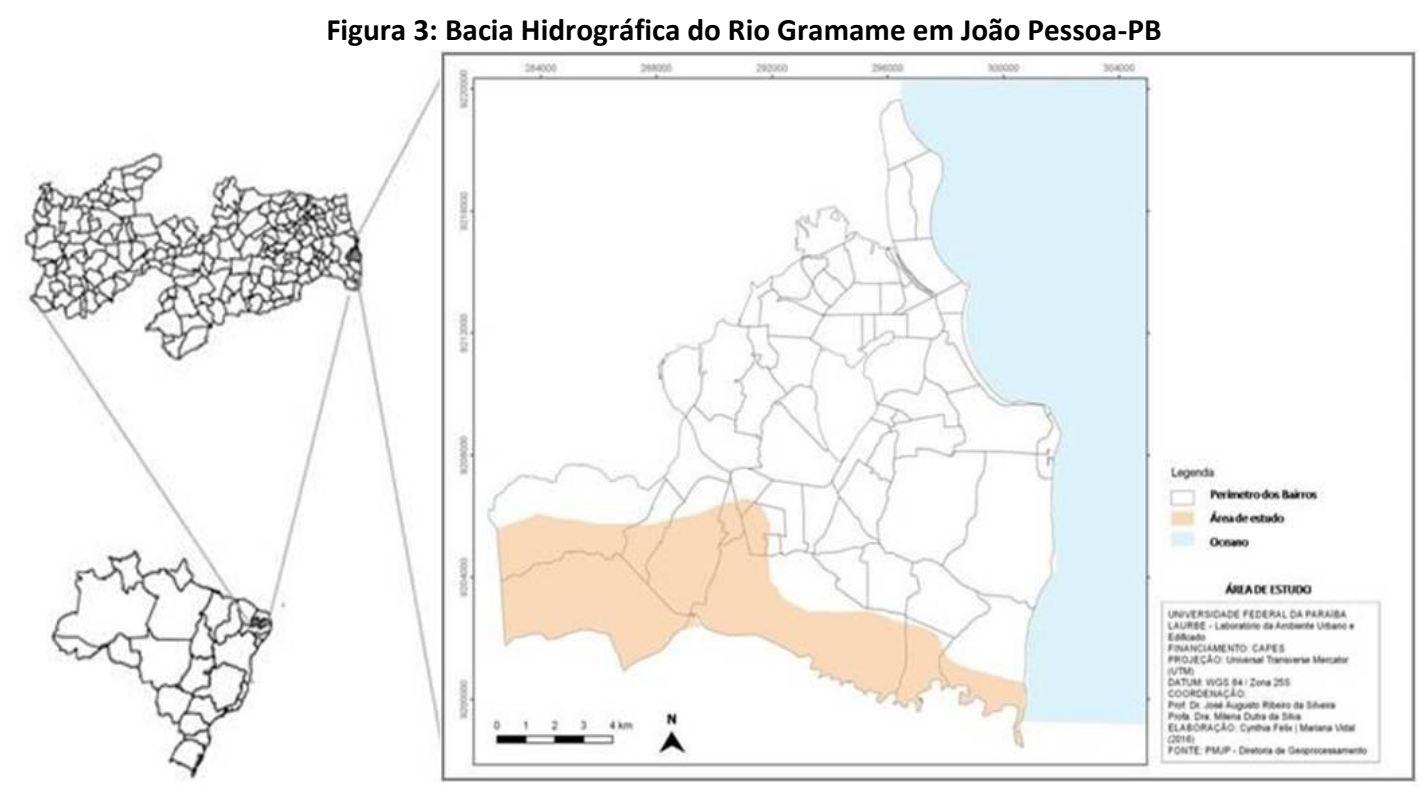

Fonte: PMJP, (2012)

Para o desenvolvimento do trabalho se fez necessário uma revisão bibliográfica prévia a fim de compreender o histórico do crescimento urbano da cidade e principalmente do recorte espacial estudado. Em seguida foram realizadas visitas de campo e consultas remotas através de ferramentas como Google Earth e Quantum Gis, que são softwares livres.

Os dados adquiridos foram espacializados, constituindo o mapeamento dos pontos de despejo de resíduos urbanos. As discussões e reflexões geradas tiveram como base tanto textos técnicos e acadêmicos como consultas a documentos dos tipos: Código de urbanismo, Código de Meio Ambiente, Estatuto da cidade, entre outros.

\section{RESULTADOS E DISCUSSÕES}

Na cidade de João Pessoa, em um intervalo temporal entre 1970 e 1985, de acordo com Silva et al., (2015), foram acrescentados aproximadamente $60,5796 \mathrm{Km}^{2}$ a área de mancha urbana no município, alcançando uma porção de $80,5302 \mathrm{Km}^{2}$ no ano de 1985 (Figura 2 e 3). A partir da década de 90 , porém, o avanço da malha urbana se deu de maneira mais amena, no entanto ainda contínua em direção ao sul da cidade, onde se localiza a área de estudo. 


\section{Periódica Eletronica}

\section{Fórum Ambiental}

Volume 14, Número 1, 2018

da Alta Paulista

ISSN 1980-0827

Figura 2: Crescimento da mancha urbana de João Pessoa, PB

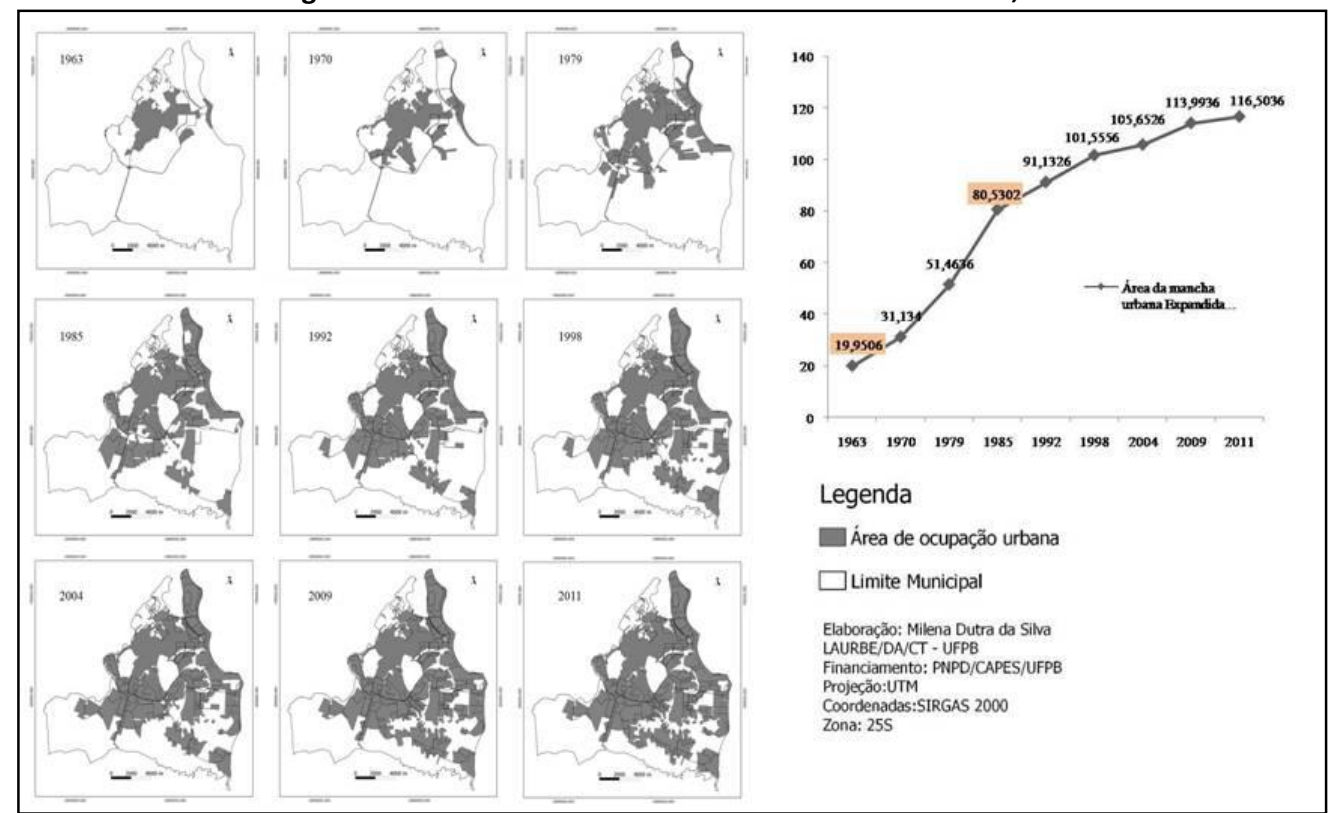

Fonte: Adaptado de Silva et al., (2015)

No recorte espacial estudado, foi possível verificar o avanço da mancha urbana da década de 60 até 2011 (Figura 3). Na área que corresponde à zona industrial iniciaram-se as primeiras implantações de indústrias e usos urbanos residenciais (Figuras 3 e 4). As manchas urbanas mais recentes e distantes do centro consolidado, e também mais próximas das áreas protegidas, encontram-se predominantemente nas áreas sul-sudeste do município (Gramame, Muçumagro e Barra de Gramame).

De acordo com Silva et al., (2015), as áreas de expressivo aumento de área urbana se justificam pelo estabelecimento de grandes vias (Avenida Cruz das Armas, dando continuidade pela BR 101 em direção ao Sul da cidade, destacada em amarelo na figura 3), e conjuntos habitacionais, considerados elementos geradores e reguladores do espaço (SILVA et al., 2015).

Figura 3: Crescimento da Mancha urbana na área de estudo.

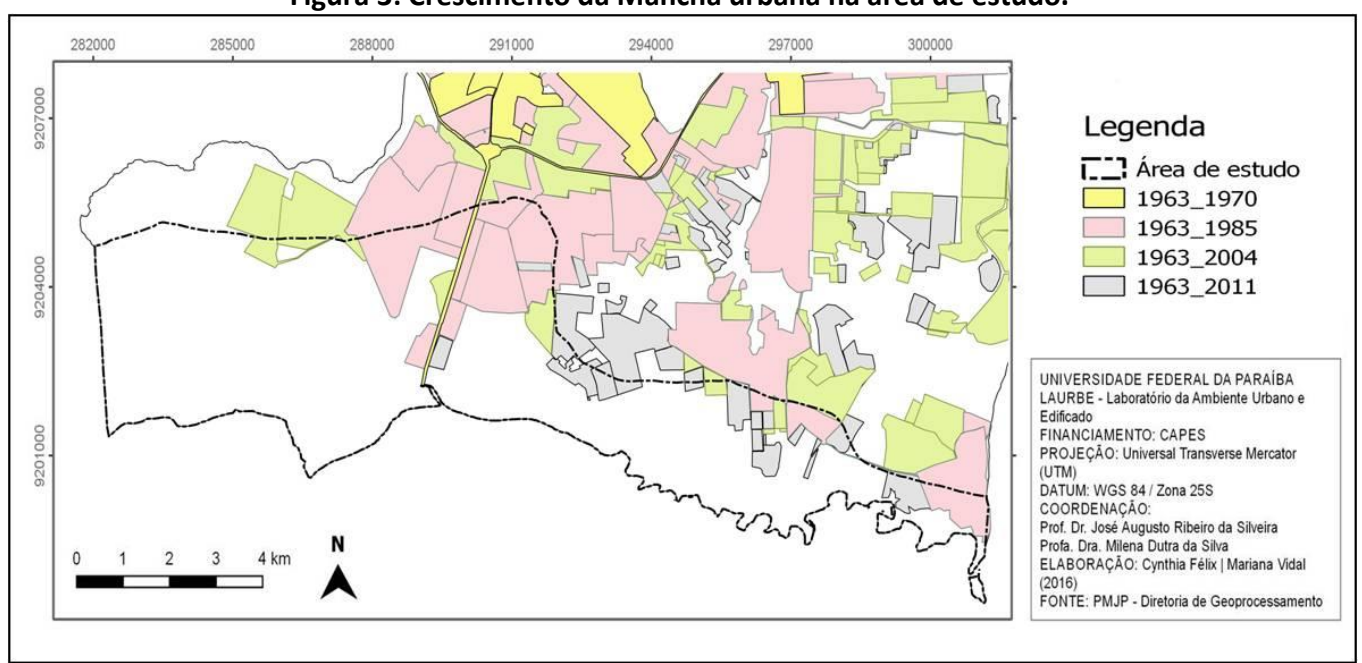

Fonte: PMJP, (2012) 


\section{Periódica Eletranica}

\section{Fórum Ambiental}

Volume 14, Número 1, 2018

da Alta Paulista

ISSN 1980-0827

Na área de estudo, fez-se um diagnóstico seguido de um mapeamento dos focos de poluição de resíduos sólidos urbanos, aqui denominados de pontos de lixo (Figura 4). Foram realizadas visitas técnicas na área de estudo, de acordo com a possibilidade de acesso de cada localidade. Assim, foram identificados ao todo 69 pontos de despejo de resíduos urbanos, espacializados na figura abaixo.

Figura 4: Localização dos Pontos de lixo na Bacia do Rio Gramame.

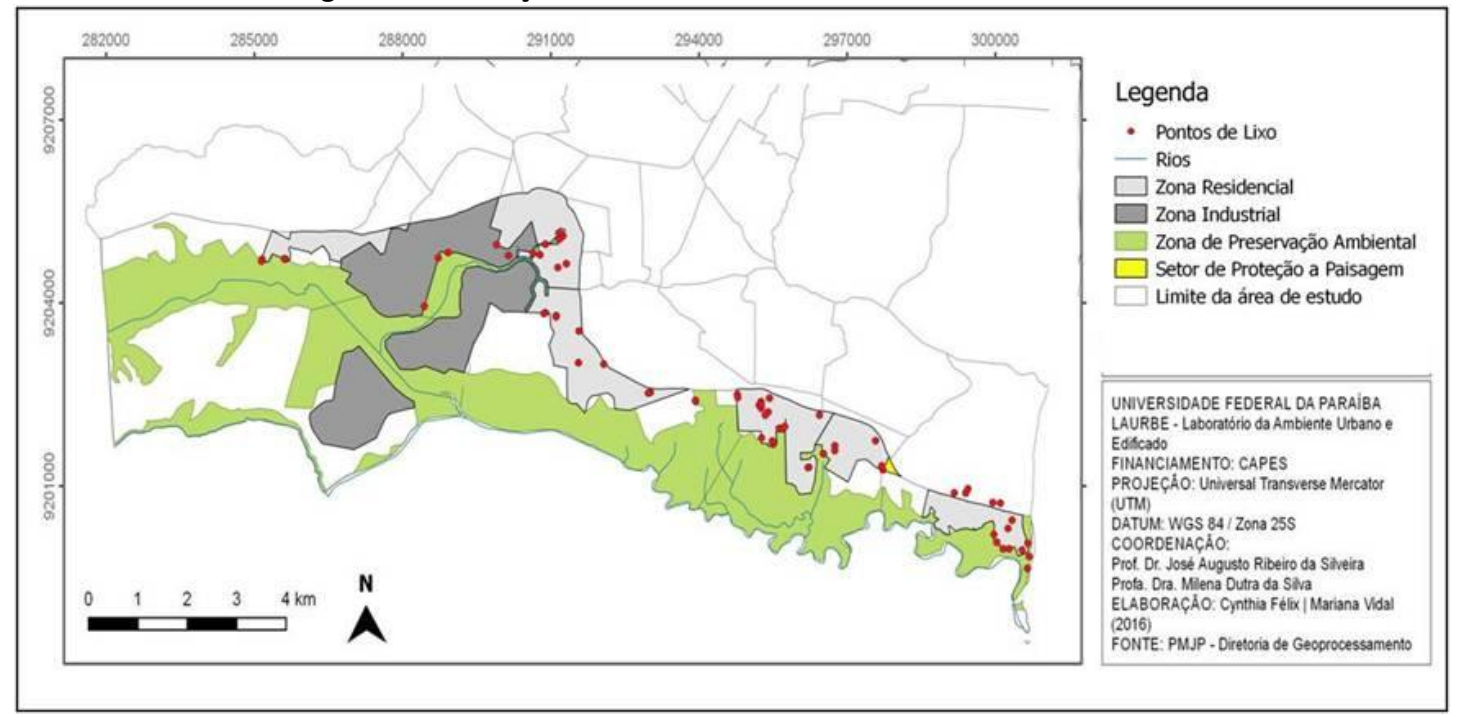

Fonte: PMJP, (2012)

Foram organizados os pontos de acordo com a localização de cada um, tendo como base o zoneamento e o macro-zoneamento da cidade de João Pessoa (tabela 1).

As zonas de proteção ambiental são destinadas a preservação das condições naturais, objetivando prevenir impactos nos ecossistemas mais sensíveis. Em João Pessoa, estas são principalmente caracterizadas pela existência de remanescentes de mata atlântica e de ambientes associados tais como: matas de restingas, matas de encosta e manguezais. Estes ambientes, pela suas características naturais caracterizam-se também pela suscetibilidade a riscos de impactos elevados.

Apesar disto, o despejo de resíduos sólidos tanto de origem domiciliar como de construção civil nas bordas destas áreas protegidas, são frequentes principalmente na Zona residencial da área de estudo (Figura 4 e Tabela 1). A segunda área de maior incidência de despejo destes resíduos são as Zonas Especiais de Proteção, apesar de sua finalidade de preservar a vegetação remanescente de Mata Atlântica do município. 


\section{Periódica Eletranica}

\section{Fórum Ambiental}

Volume 14, Número 1, 2018

da Alta Paulista

ISSN 1980-0827

Tabela 1: Quantificação dos pontos de resíduos alocados por zonas.

\begin{tabular}{c|l|l}
\hline $\begin{array}{c}\text { Quantificação } \\
\text { dos pontos. }\end{array}$ & \multicolumn{1}{|c}{ Zona } & \multicolumn{1}{c}{ Descrição da zona } \\
\hline 41 & $\begin{array}{l}\text { Zona Residencial 2 } \\
\text { (corresponde a Zona } \\
\text { não Adensável no } \\
\text { macrozoneamento, } \\
2012)\end{array}$ & $\begin{array}{l}\text { Corresponde às áreas destinadas a usos predominantemente } \\
\text { residenciais. }\end{array}$ \\
\hline 24, sendo 3 no & $\begin{array}{l}\text { Zonas Especiais de } \\
\text { Proteção 2 } \\
\text { a Zi1. }\end{array}$ & $\begin{array}{l}\text { Áreas protegidas por instrumentos legais diversos devido à } \\
\text { existência de remanescentes de mata atlântica e de ambientes } \\
\text { associados tais como: matas de restingas, matas de encosta e } \\
\text { manguezais, assim como à suscetibilidade do meio a riscos } \\
\text { elevados. (Código de Urbanismo de João Pessoa, 2001) }\end{array}$ \\
\hline 02 & $\begin{array}{l}\text { Zona Industrial 1 } \\
\text { (corresponde a Zona } \\
\text { Adensável Não } \\
\text { Prioritária no } \\
\text { macrozoneamento, } \\
\text { 2012) }\end{array}$ & $\begin{array}{l}\text { Área do território do município na qual é permissível a } \\
\text { implantação de estabelecimentos industriais, de modo a } \\
\text { assegurar à oferta de terrenos destinados a implantação de } \\
\text { empreendimentos industriais ou correlatos. O intuito é evitar os } \\
\text { efeitos danosos a população e ao meio ambiente. (Código de } \\
\text { Urbanismo de João Pessoa, 2001) }\end{array}$ \\
\hline $\begin{array}{l}\text { Setor de Proteção a } \\
\text { Paisagem } \\
\text { (corresponde a Zona de } \\
\text { Preservação ambiental } \\
\text { no macrozoneamento, } \\
\text { 2012) }\end{array}$ & $\begin{array}{l}\text { Área destinada à função de desacelerar a expansão urbana } \\
\text { garantindo a preservaça de paisagem singular e/ou de resquícios } \\
\text { de Mata Atlântica permitindo uma ocupação sustentável } \\
\text { priorizando usos característicos da zona rural. (Lei complementar } \\
\text { No 054, João Pessoa, 2008) }\end{array}$ \\
\hline
\end{tabular}

Fonte: Dados da Pesquisa (2016)

No Bairro de Mumbaba, localizado ao sul-sudeste, é verificável a existência de pontos de lixo nas bordas da zona de preservação ambiental, onde é verificada a disposição de resíduos domésticos e de construção civil (Figura 5). Esta prática constitui perigo para o equilíbrio ambiental, tendo em vista que compostos líquidos e semi-sólidos são facilmente lixiviados, chegando a contaminar os cursos d água, impactando negativamente o ambiente (MARQUES, 2011).

Os impactos ambientais podem ser definidos como qualquer alteração das propriedades físicas, químicas e/ou biológicas do ambiente, provocada de maneira direta ou indireta, provenientes de atividades humanas que podem afetar a saúde, a segurança e/ou a qualidade dos recursos naturais (FOGLIATTI et al., 2004). 


\section{Periódica Eletrânica}

\section{Fórum Ambiental}

Volume 14, Número 1, 2018

da Alta Paulista

ISSN 1980-0827

Figura 5: Ponto de despejo de resíduos domésticos e da construção civil na borda da ZPA. Bairro Mumbaba.

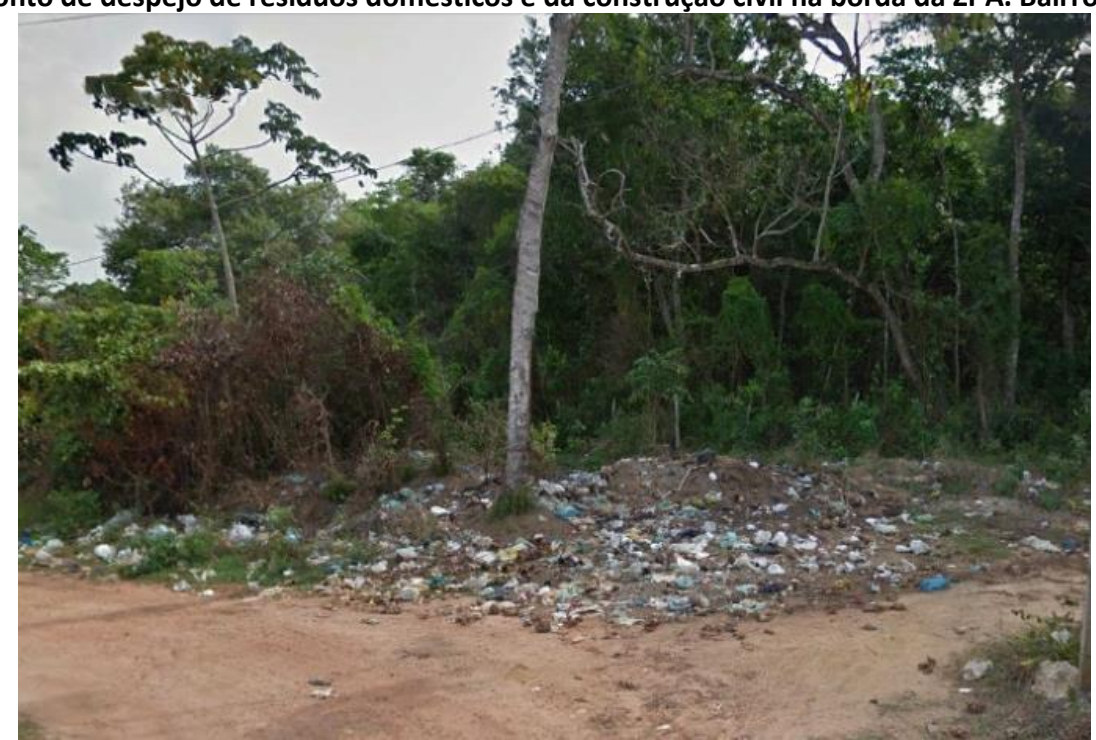

Fonte: Fotografia Google Earth, (2016)

O acondicionamento dos resíduos em containeres e demais recipientes ajudam a impedir o contato dos resíduos com o solo, contribuindo na prevenção da poluição proveniente da decomposição e derramamento de diversos compostos dos resíduos.

Durante o processo de decomposição dos resíduos sólidos urbanos ocorre a geração de gases como metano ( $\mathrm{CH} 4$ ), óxidos de nitrogênio (NOx), óxidos de enxofre (SOx), e dióxido de carbono (CO2). A presença desses gases na atmosfera contribui para fenômenos como a chuva ácida e o efeito estufa, além de serem tóxicos para diversos organismos, inclusive para os seres humanos. Parte desses poluentes é liberada constantemente na atmosfera, principalmente quando não há tratamento, acondicionamento ou disposição adequados dos resíduos (MARQUES, 2011).

Apesar disto, é comum na Bacia hidrográfica do rio Gramame o acondicionamento direto no solo, configurando focos de poluição urbana que impactam o meio ambiente e a paisagem. Estes mesmos resíduos muitas vezes são queimados e abandonados no local como ocorre, por exemplo, no Bairro de Gramame (Figura 6).

Frequentemente observa-se também a formação de terrenos baldios utilizados para o despejo dos resíduos da construção civil, despejados diretamente no solo, impactando com maior evidência a paisagem.

Os resíduos da construção civil (RCC) de acordo com a Lei no12.305/2010, são aqueles gerados nas construções, reformas, reparos e demolições de obras de construção civil, incluindo os resultantes da preparação e escavação de terrenos para obras civis. 


\section{Periódica Eletrônica \\ Fórum Ambiental}

Volume 14, Número 1, 2018

da Alta Paulista

ISSN 1980-0827

Figura 6: Ponto de lixo proveniente da construção civil (à esquerda) e prática de queima de resíduos domésticos e verdes em terreno baldio. Bairro Gramame.
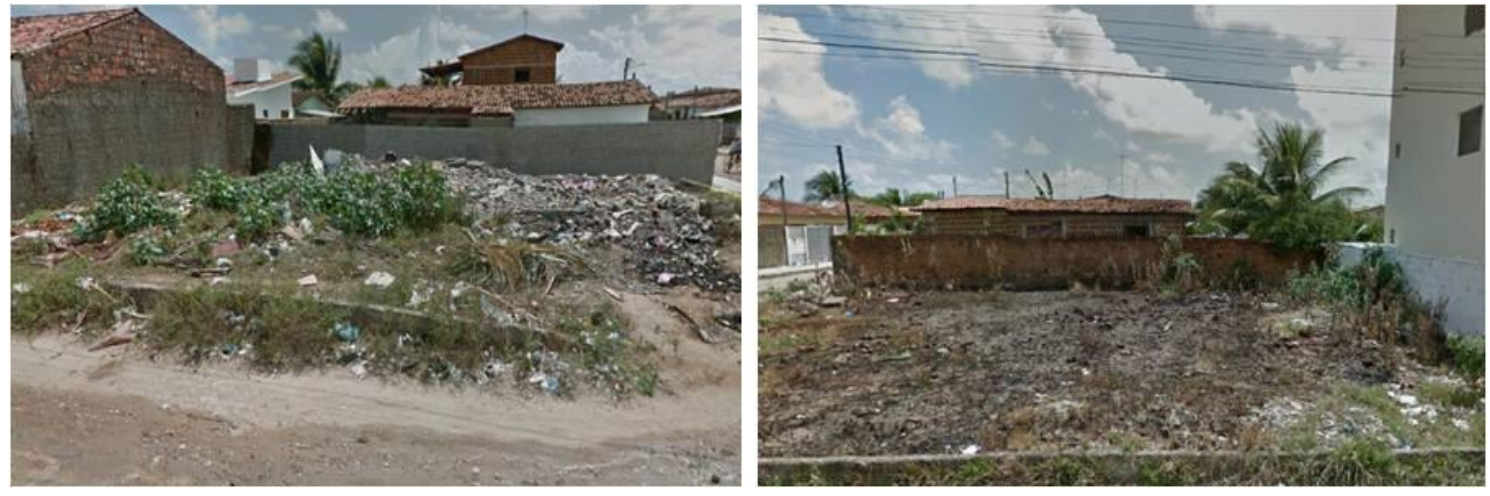

Fonte: Dados da Pesquisa

A degradação do solo, que de acordo com Oliveira (2005) pode ocorrer em suas propriedades físicas (estrutura, porosidade, compacidade), químicas $(\mathrm{pH})$ e biológicas (microrganismos), é um aspecto pouco considerado, mas de imensa relevância, pois é sobre o solo que a maioria das atividades humanas são realizadas (da construção de edificações até produção de alimentos). Em Barra de Gramame, na área correspondente ao setor de proteção à paisagem é possível verificar juntamente aos lotes lá inseridos, a mesma problemática, conflitando com a finalidade de uso sustentável desta tipologia de zona (Figura 8).

Figura 8: Despejo de resíduos domésticos e da construção civil no Setor de Proteção a Paisagem correspondente ao bairro Barra de Gramame.
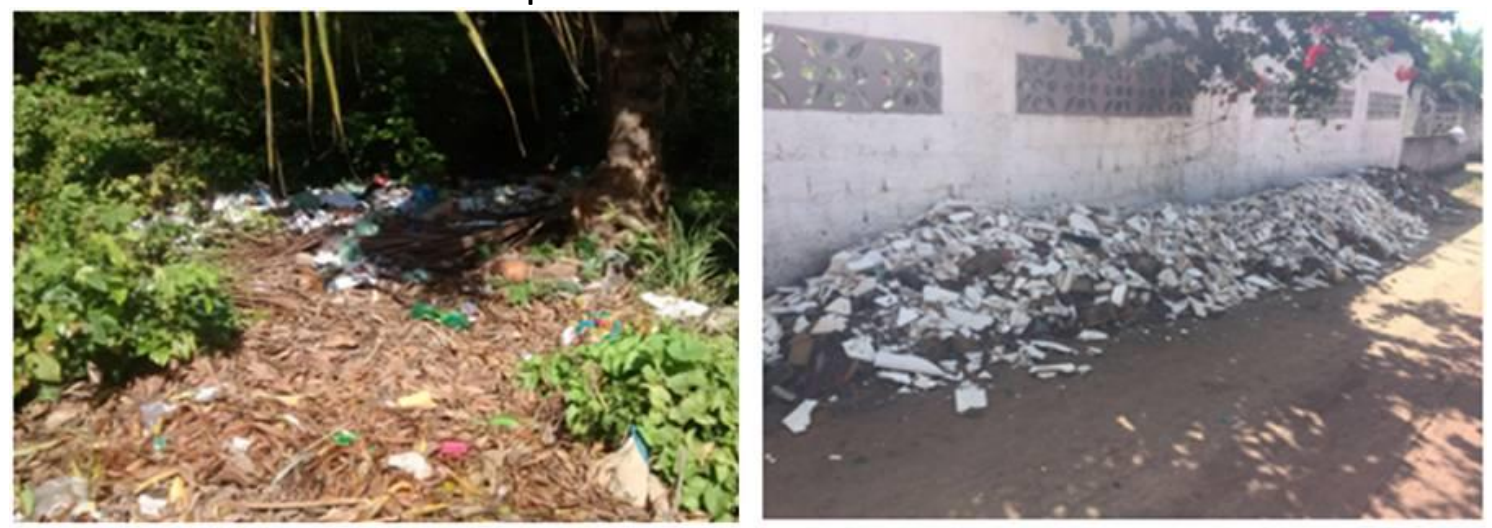

Fonte: Dados da pesquisa

Tendo como base o percentual de composição dos resíduos urbanos que tende a variar de acordo com diferentes fatores, Silva, (2015), mostra que é possível diagnosticar que a incidência de resíduos domésticos e da construção civil está associada à implantação de novas edificações. No procedimento de coleta dos resíduos dos pontos de lixo realizado pela prefeitura, é retirada grande parte dos resíduos, porém parte do solo também é eliminada, acarretando na perda do potencial de conservação do mesmo (Figura 9).

A falta de medidas de conservação do solo urbano permite o aparecimento e a intensificação dos impactos ambientais por meio da degradação solo. A degradação do solo pode ser entendida como o processo e resultado de atividades antrópicas impróprias, que chegam a provocar a redução de sua qualidade, impactando ecossistemas e produzindo áreas cada vez mais inutilizáveis. 


\section{Periódica Eletranica}

\section{Fórum Ambiental}

Volume 14, Número 1, 2018

da Alta Paulista

ISSN 1980-0827

A NBR 10703 (ABNT, 1989), por sua vez, trás como definição de degradação do solo a "alteração adversa das características do solo em relação aos seus diversos usos possíveis, tanto os estabelecidos em planejamento quanto os potenciais".

Segundo Reinert, (1998) apud Magalhães, (2005), podem ser elencados três principais tipos de degradação do solo: a degradação física, que se refere às condições ligadas à forma e estabilidade da estrutura do solo; a degradação biológica, que está associada com a redução da matéria orgânica, atividade e diversidade de organismos; e a degradação química, que é reflexo da retirada e saída de nutrientes por acúmulo de elementos tóxicos e/ou desbalanceados no solo.

Figura 9: Solo retirado no processo de recolhimento dos resíduos despejados. Bairro Funcionários.

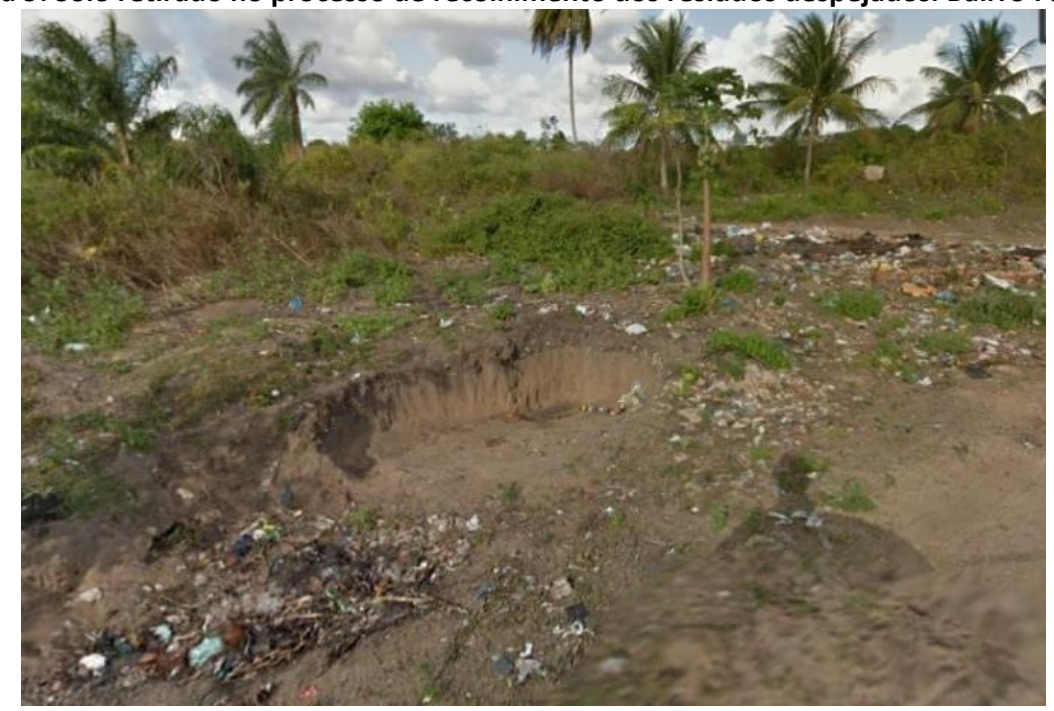

Fonte: Fotografia Google Earth, (2016)

De acordo com Marques, (2011), entre os principais efeitos da presença dos resíduos urbanos em corpos hídricos podem ser citados: a elevação da demanda bioquímica de oxigênio, redução dos níveis de oxigênio dissolvido, formação de correntes ácidas, maior carga de sedimentos, elevada presença de coliformes, aumento da turbidez e intoxicação de organismos presentes naquele ecossistema, incluindo o homem, quando este utiliza água contaminada para consumo. Em um trecho do Riacho Mussuré os resíduos sólidos urbanos são frequentemente despejados diretamente no rio, que já passa por um processo antigo de poluição de diversas origens (Figura 10). 


\section{Periódica Eletrânica}

\section{Fórum Ambiental}

Volume 14, Número 1, 2018

da Alta Paulista

ISSN 1980-0827

Figura 10: Poluição por resíduos sólidos no rio Riacho Mussuré. Bairro Funcionários.

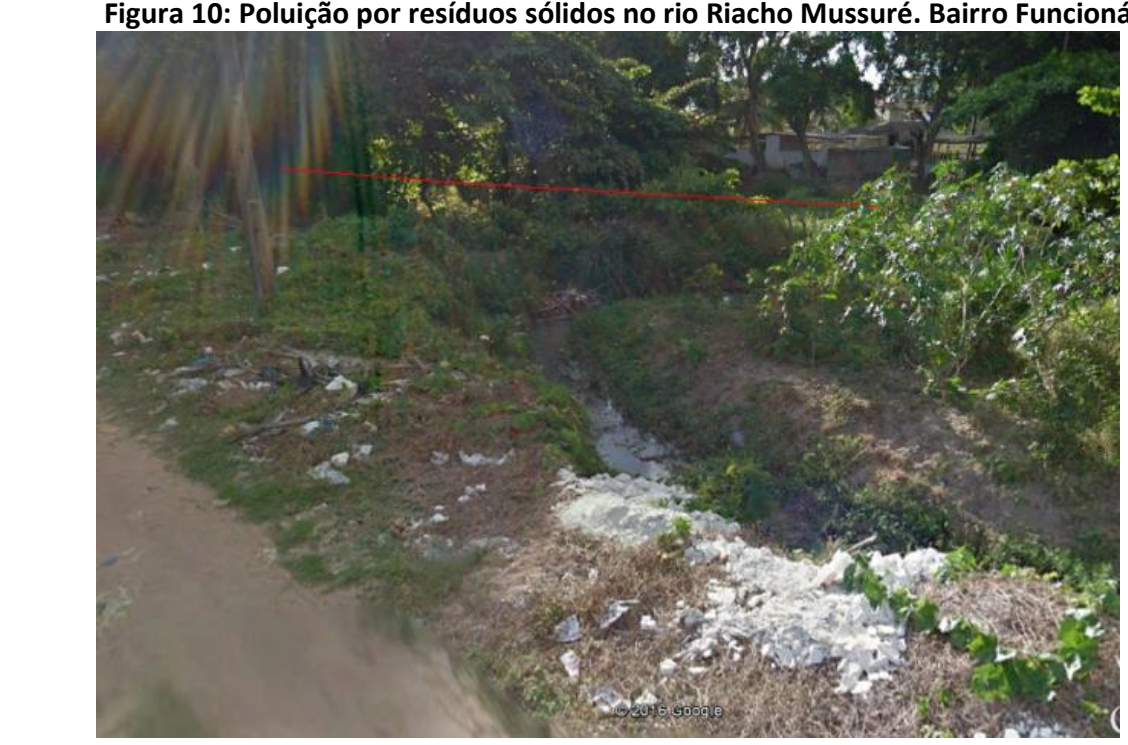

Fonte: Fotografia Google Earth, (2016)

A problemática dos resíduos urbanos na Bacia do Rio Gramame em João Pessoa evidencia a necessidade de melhoria e efetivação das políticas de proteção ambiental, que envolvem inclusive medidas de fiscalização. A presença de pontos de lixo foi mais expressiva nas áreas que correspondem à zona residencial e nas Zonas de Preservação Ambiental.

A proteção do solo também se encontra negligenciada conforme foi apresentado também na figura 9.

As áreas de preservação constituem hoje fragmentos de espaços naturais de extrema importância para o equilíbrio ambiental, no entanto sofrem com intenso e constante espraiamento urbano direcionado para as áreas mais ambientalmente sensíveis, comprometendo as condições ambientais como um todo.

\section{CONSIDERAÇÕES FINAIS}

A urbanização do município João Pessoa se deu de maneira rápida e dispersa, direcionada para o sul do município, área caracterizada pelos grandes espaços naturais necessários a qualidade ambiental, como por exemplo, a Bacia do Rio Gramame. Esta pesquisa se propôs a diagnosticar os impactos ambientais urbanos decorrentes da disposição de resíduos na referida área de estudo. Esperouse com esta pesquisa, contribuir nos conhecimentos acerca das temáticas relativas aos impactos ambientais associados à urbanização dispersa das cidades.

A partir dos resultados discutidos, foi possível concluir que a presença de resíduos sólidos urbanos está associada a usos urbanos, principalmente a usos residenciais.

Os dados ainda revelaram haver uma tendência para a disposição dos resíduos e formação de pontos de lixo em terrenos baldios nas Zonas de preservação ambiental e em áreas de preservação permanente.

A prática de disposição dos resíduos é impactante ao solo principalmente na etapa de recolhimento, ao retirar parte de sua camada superficial. A existência destes pontos de lixo nas Zonas de preservação ambiental configura conflito de uso, tendo em vista a finalidade de proteção destas áreas.

O frequente descarte de resíduos da construção civil indicou movimento deste setor de serviços, principalmente para a inserção de novas edificações. 
Também foi possível concluir que a densidade populacional pode estar associada à quantidade de pontos de lixo nas zonas residenciais. No entanto, é necessário investigar esta questão especificamente no que ser refere à variação das densidades ocupacionais em determinadas áreas e suas relações com os pontos de lixo existentes.

\section{AGRADECIMENTOS}

Os autores agradecem a CAPES (Comissão de Aperfeiçoamento de Pessoal do Nível Superior) pelo apoio e financiamento da pesquisa através da concessão de bolsa de estudos.

\section{REFERENCIAS BIBLIOGRÁFICAS}

ASSOCIAÇÃO BRASILEIRA DE NORMAS TÉCNICAS. NBR 10703. Degradação do solo: terminologia. Rio de Janeiro, 1989.

BRASIL. Lei no 12.305, de 2 de agosto de 2010. Institui a Política Nacional de Resíduos Sólidos; altera a Lei. 9.605, de 12 de fevereiro de 1998; e dá outras providências. Disponível em: <http://www.mma.gov.br/port/conama/legiabre.cfm?codlegi=636>. Acesso em: 21 de out. 2015.

CARDOSO, Marcelle Alves; MOTA, Pablo Diego M.; SILVA, Luciana Carvalho da; MONTEIRO, Sibelle Cavalcante; FERREIRA, José F. C. O despejo de resíduos sólidos nas ocupações irregulares no canal do Jandiá (Macapá-AP). Revista Nacional de Gerenciamento de Cidades, v. 03, n. 19, p. 149-161, 2015.

FOGLIATTI, M. C.; FILIPPO, S.; GOUDARD, B. Avaliação de impactos ambientais: aplicação aos sistemas de transporte. Rio de Janeiro: Interciência, 2004. 249 p.

MAGALHÃES, A. F. Avaliação do desempenho de técnicas de bioengenharia na proteção e conservação da cobertura final de taludes em aterros de disposição de resíduos sólidos urbanos: estudo de caso para o Aterro Sanitário de Belo Horizonte, MG. 2005. 169 f. Dissertação (Mestrado em Saneamento, Meio Ambiente e Recursos Hídricos) - Universidade Federal de Minas Gerais, Belo Horizonte, 2003.

MARQUES, Rosângela Francisca de Paula Vitor. Impactos ambientais da disposição de resíduos sólidos urbanos no solo e na água superficial em três municípios de Minas Gerais. Dissertação (mestrado) - Universidade Federal de Lavras, 2011;

OLIVEIRA, Caue Nascimento de. Recuperação ambiental de aterros sanitários na região metropolitana de Campinas: revegetação e uso futuro. 2005. Dissertação (Mestrado em Engenharia Civil)- Faculdade de Engenharia Civil. Arquitetura e Urbanismo. Universidade Estadual de campinas, 2005.

PANTALENA, Ana Flávia; MAIA, Luis Parente. Marcas da ação antrópica na história ambiental do Rio Jaguaribe, Ceará, Brasil. Revista de Gestão Costeira Integrada/Journal of Integrated Coastal Zone Management, v.14, n.3, p. 459-469, 2014. 
PMJP. Mapas e Zoneamento. João Pessoa. Disponível em: < Prefeitura Municipal de João Pessoa. http://www.joaopessoa.pb.gov.br/legislacao/mapas-e-zonamento/>. Acesso em: 30 de jan de 2016.

SILVA, Rodrigo Cordeiro da; NOTARO, Krystal de Alcântara. RCC - resíduos da construção civil caracterização de sua gestão integrada: um estudo de caso a área urbana de Garanhuns-PE. Revista Nacional de Gerenciamento de Cidades. v. 3, n. 22, p. 64-77, 2015.

SILVA, Brunielly de Almeida. SILVA, Milena Dutra da; SILVEIRA, José Augusto Ribeiro da;Distensão Intraurbana: Os espaços periféricos limítrofes da cidade de João Pessoa. In: SILVEIRA, José Augusto Ribeiro da. SILVA, Milena Dutra da Silva; CASTRO, Alexandre Augusto Bezerra da C.,(Organizadores). Dinâmica da cidade e bordas urbanas. João Pessoa, PB: F\&A. 74103. 2015.

SILVA, Milena Dutra da; CASTRO, Alexandre Augusto Bezerra da C.; SILVA, Brunielly de Almeida Silva; SILVA, Geovanny Jessé Alexandre da Silva; SILVEIRA, José Augusto Ribeiro da.Crescimento da mancha urbana da cidade de João Pessoa, PB. In: SILVEIRA, José Augusto Ribeiro da. SILVA, Milena Dutra da Silva; CASTRO, Alexandre Augusto Bezerra da C.,(Organizadores). Dinâmica da cidade e bordas urbanas. João Pessoa, PB: F\&A. 54-72. 2015 SILVA, José da.O Novo Rural Brasileiro. Campinas: Unicamp, 2002. 